\title{
Aproximaciones al cómic Chanoc. Entretenimiento y enseñanza
}

An Approach to the Comic Book of Chanoc. Entertainment and Teaching

Abordagens para o Chanoc cômico. Entretenimento e ensino

Marina Ruano Gutiérrez

Universidad de Guadalajara, México marinaruano@yahoo.com https://orcid.org/0000-0002-7098-9980

Irma Angélica Bañuelos Ávila

Universidad de Guadalajara, México irmaisla@hotmail.com https://orcid.org/0000-0001-6822-4471

Roberto Herrera Gallardo Universidad de Guadalajara, México robertoletrashispánicas@gmail.com https://orcid.org/0000-0002-6704-6295 


\section{Resumen}

El propósito de este trabajo consiste en analizar el cómic Chanoc, específicamente la construcción del personaje principal, la figura del héroe, la narrativa, el lenguaje popular, la aparición de palabras científicas, la figura de Tsekub Baloyán, compañero y padrino de Chanoc, el entretenimiento y la función didáctica de la historieta. Se propone identificar los elementos sobresalientes del cómic y establecer la relación de estos elementos con el público lector. Esto a través de tres métodos de análisis: la narratología, la estilística y la exégesis. Como parte de los resultados, el cómic Chanoc, a través de personajes representativos, instruye a los jóvenes por medio de la crítica social, crea conciencia y da lecciones sobre el comportamiento de los animales y el cuidado de la naturaleza.

Palabras clave: cómic, héroe, lenguaje popular, narrativa.

\section{Abstract}

The purpose of this work is to analyze the comic Chanoc, specifically the construction of the main character, the figure of the hero, the narrative, the popular language, the appearance of scientific words, the figure of Tsekub Bayolán, Chanoc's partner and godfather, the entertainment and the didactic function of the comic. It is proposed to identify the outstanding elements of the comic and establish the relationship of these elements with the reading public. This through three methods of analysis: narratology, stylistics and exegesis. As part of the results, it stands out that the Chanoc comic, through representative characters, instructs young people through social criticism, creates awareness and gives lessons on the behavior of animals and the care of nature.

Keywords: comic, hero, folk language, narrative. 


\section{Resumo}

O objetivo deste trabalho é analisar a história em quadrinhos de Chanoc, especificamente a construção do personagem principal, a figura do herói, a narrativa, a linguagem popular, o surgimento de palavras científicas, a figura de Tsekub Baloyán, parceiro e padrinho de Chanoc, o entretenimento e a função didática do desenho animado. Propõe-se identificar os elementos marcantes do quadrinho e estabelecer a relação desses elementos com o público leitor. Isso por meio de três métodos de análise: narratologia, estilística e exegese. Como parte dos resultados, o gibi Chanoc, por meio de personagens representativos, instrui os jovens por meio da crítica social, cria consciência e dá aulas sobre o comportamento dos animais e os cuidados com a natureza.

Palavras-chave: quadrinhos, herói, linguagem popular, narrativa.

Fecha Recepción: Marzo 2020

Fecha Aceptación: Diciembre 2020

\section{Introducción}

Los cómics son un medio expresivo considerado como el noveno arte o arte conceptual. En Europa, el cómic inicia en la década de 1830 con las tiras cómicas del suizo Rodolphe Töpffer; en Estados Unidos comienza en 1890 con la tira cómica The Yellow Kid de Richard F. Outcault (L., 2014), quien en 1896 publica la primera tira cómica regular en el suplemento dominical del diario New York World, y en Japón el cómic tiene sus orígenes antes de la Segunda Guerra Mundial. A mediados del siglo XX, considerada la edad de oro del cómic, se hace popular principalmente en Francia, Bélgica, Estados Unidos y Japón, a través de periódicos, libros y revistas. Los cómics surgieron como un nuevo modo de expresión e información. Los periódicos recurrían a ellos para atraer a los lectores, y así se convirtieron en un medio de comunicación de masas.

En México, los primeros cómics aparecen en las páginas de los periódicos. Para los años 40, el cómic tiene un mayor auge y comienza a ser visto como un "vehículo eficaz, sencillo y barato para llevar el hábito de la lectura" (Morrison, 2017). En este país el cómic generalmente trata temas políticos y sociales (Maza, 2013, p. 14). Entre los grandes artistas de la historieta mexicana se encuentran: Yolanda Vargas Dulché como creadora y Sixto Valencia Burgos como dibujante de Memín Pinguín (1943), Gabriel Vargas con La Familia 


\section{Revista Iberoamericana \\ de las Ciencias Sociales y Humanísticas}

ISSN: 2395 - 7972

Burrón (1948), Eduardo del Río (Rius) con Los Supermachos y Óscar González Loyo, autor de Karmatrón y Los Transformables.

En 1959, el guionista Ángel Martín de Lucenay se asoció con el dibujante tabasqueño Ángel Mora, gracias a la intermediación de Carlos Vigil, para iniciar un nuevo proyecto en Publicaciones Herrerías basado en un guión cinematográfico que le habían rechazado a Ángel (Fernández, 2018, p. 9). Se trataba de Chanoc. Aventuras de mar y selva, que se publicó por primera vez en ese mismo año, 1959, en un formato tradicional en México de 32 páginas. Este fascículo estaba impreso a color. Luego de esa primera edición, nuevos números se fueron publicando semanalmente los días viernes. Para este trabajo se ha consultado el material digitalizado por Camarada05 (Camarada05, 2014), que comprende el original de la historieta completa.

Chanoc es un cómic de aventuras y acción que se desarrolla en el imaginario puerto de Ixtac, situado en la zona maya del Golfo de México, su popularidad se sostuvo por más de 20 años y tuvo su mayor esplendor entre 1960 y 1970. La historieta se basa en personajes característicos de un pueblo costeño: Chanoc (el protagonista, pescador y aventurero), Tsekub (padrino de Chanoc), Pata Larga (el farero), Maley (la novia de Chanoc), el tendero, el brujo, el curandero, el pelón, caníbales y pigmeos, además de una serie personajes míticos. La infancia de Chanoc, la pesca, algunos enfrentamientos con animales peligrosos, Chanoc y sus distintos rivales, la medicina ancestral y el microcosmos, entre otros, eran algunos de los temas que se presentaban. A lo largo de las páginas del cómic, el autor deja ver su afición por la cultura popular e intercala elementos del cine, la música, el futbol y la televisión.

Sin duda, este cómic cumple con una función didáctica. Las enseñanzas que transmite tienen que ver principalmente con un comportamiento moralmente bueno del ser humano, con la prudencia y la obediencia, confiar en la justicia y no ejercer la venganza y el respeto a la vida. También persuade al lector sobre el respeto y la protección de la flora y la fauna, y da lecciones sobre el comportamiento natural de algunos animales 
Revista Iberoamericana

de las Ciencias Sociales y

Humanísticas

ISSN: $2395-7972$

\section{Metodología}

La metodología empleada para el estudio y análisis del cómic en cuestión está basada en tres métodos de análisis: 1) la exégesis, para considerar los aspectos que forjan el carácter del personaje principal desde su niñez, 2) la estilística, para la caracterización de Tsekub, socio épico de Chanoc, y donde se consideran también los aspectos de Tsekub el pícaro, el entorno ficcional, los elementos contextuales de la época, el microcosmos de la mexicanidad y Tsekub el apolíneo y dionisiaco tropical y 3) la narratología, para estudiar los usos del lenguaje popular citadino y el lenguaje científico.

Figura 1. Portada del libro Chanoc. Aventuras de mar y selva.

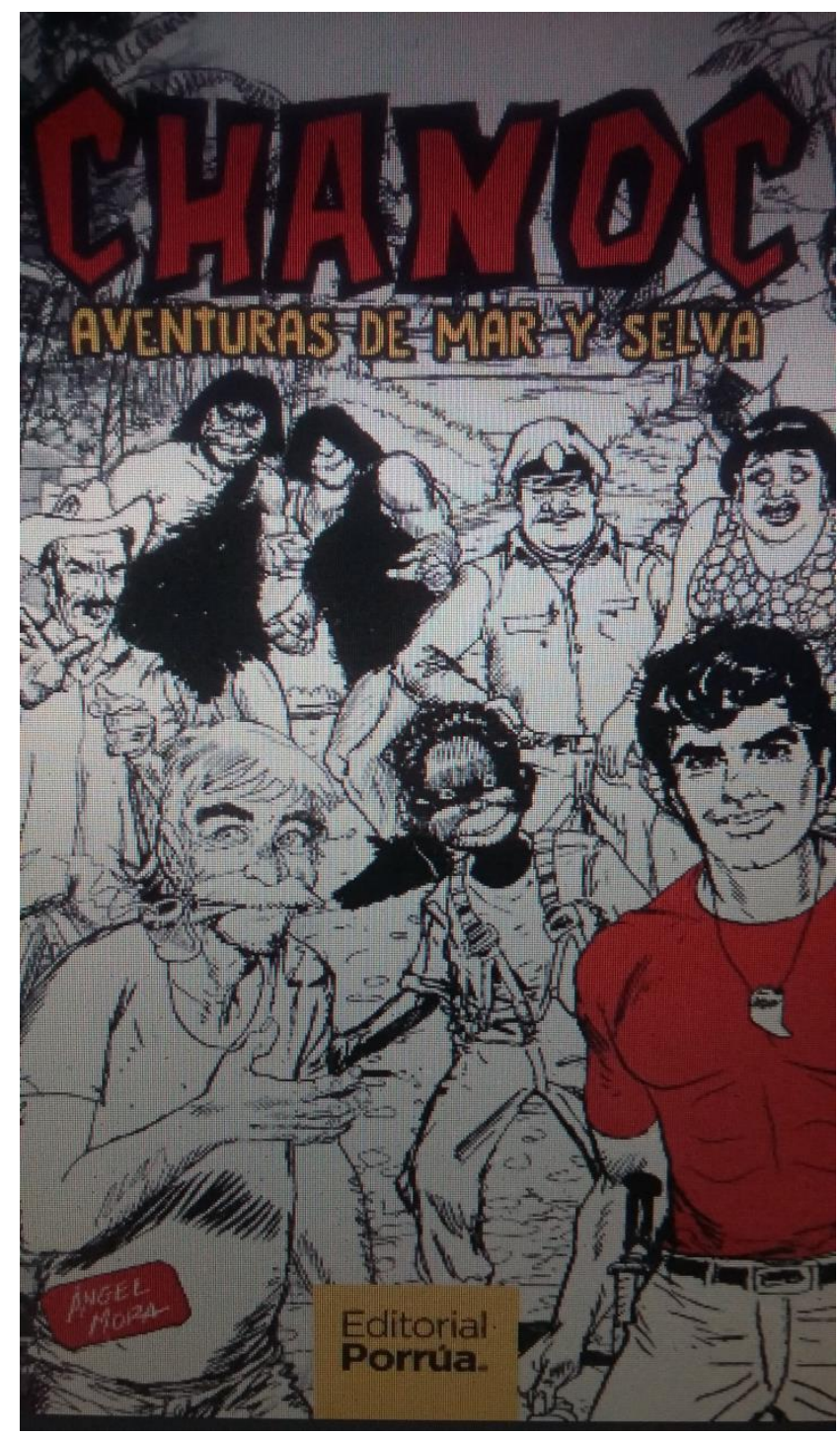

Fuente: Mora (2018) 


\section{Resultados}

\section{Construcción del personaje}

En la figura 1, correspondiente a la portada del primer número del cómic, se pueden apreciar a los distintos personajes que conforman la historieta, y resalta en rojo la imagen del personaje principal. Para comprender el desenvolvimiento de Chanoc, el personaje principal del cómic, habría que remontarse al número 001 del cómic, sin título visible, publicado en 1959. Este primer número ofrece un recuento de la infancia de Chanoc y sienta las bases sobre la personalidad y las habilidades del personaje. Pero antes de continuar hay que recordar que la suma de "códigos preexistentes y reconocibles" (Eco, 1986, p. 226), aunado a los “códigos gestálticos convencionales” (Eco, 1986, p. 227), permiten recrear la construcción de un personaje. Y que, de acuerdo con Cuñarro y Finol (2013), "la acción de narrar es describir o referir una sucesión de hechos mediante la utilización de códigos icónicos y lingüísticos. Generalmente están enmarcados en un periodo de tiempo" (p. 284).

Ahora bien, como ya habíamos mencionado líneas arriba, en este primer número del cómic se muestra a Chanoc desde la niñez hasta llegar a la edad adulta. Con una narración en "estilo indirecto (tercera persona)" (Cuñarro y Finol, 2013, p. 284), se describe a un niño inquieto que aprende de Pedro, su padre, que le enseña a manejar la estaca, y de Tsekub, su padrino, que lo instruye en el manejo del cuchillo. En el avance de esta historieta se recurre igualmente "al estilo directo (diálogos enmarcados en globos)" (Cuñarro y Finol, 2013, p. 285).

Así pues, con una serie de aventuras ilustradas con íconos y una narrativa de códigos emotivos, se presenta la forma en que, por primera vez, Chanoc mata a un jaguar de un estacazo en la cabeza y cómo, a pesar de ya estar muerto, manifestando un carácter impulsivo, le repite el garrotazo. A la manera de la épica homérica, se establece una relación de la valentía consanguínea que resalta las hazañas heroicas de su padre que mató a un puma cuando apenas tenía nueve años. La figura de Chanoc, al frente del espacio virtual, "ventana o la cuarta pared" (Cuñarro y Finol, 2013, p. 286), mirando al lector, afirma que la fuerza que le vino fue resultado del miedo al verse frente al jaguar. El tema del miedo, expresado con códigos emotivos, es recurrente cada vez que Chanoc se enfrenta a algún animal. Enseguida, los compadres matan a la jaguar, Chanoc la encuentra 


\section{Revista Iberoamericana de las Ciencias Sociales y Humanísticas}

ISSN: $2395-7972$

moribunda, le ofrece líquido para beber, la jaguar muere y Chanoc adopta al cachorro y decide criarlo hasta que sea grande. En la figura de Chanoc se enlazan distintos sentimientos. Por un lado, la valentía de un héroe y, por el otro, el miedo y la compasión de un ser humano. La narración secuencial formada por los pequeños cuadros (Ceballos, 2018) da cuenta de una serie de aventuras que le acontecen a Chanoc entre las que sobresalen dos en las que su amigo, la cría de jaguar, lo salva del ataque de una víbora de cascabel y de un tiburón.

Los padres de Chanoc (Pedro y Naytab) mueren atacados por tiburones cuando se dirigían a la Isla Corral para comprarle un regalo por haber aprobado todas sus materias en la escuela. Ante la pérdida de sus padres, con su rostro ocupando toda la viñeta, en un

ángulo de visión a nivel de los ojos, Chanoc promete matar a todos los tiburones a cuchilladas. A partir de ahí, Tsekub se convierte en el mentor y en el amigo inseparable de Chanoc. 15 años más tarde aparece Chanoc dando cumplimento a su promesa: ha matado tantos tiburones que cree haberlos matado a todos, y se distingue lo vengativo como una característica más del personaje. Al final aparece Maley, una joven a quien Chanoc salva del ataque de un puma. En este segmento, Chanoc se comporta caballeroso y respetuoso con Maley. El cómic de Chanoc carece de onomatopeyas cuando se mata a los animales, el sufrimiento del animal no se deja ver en las viñetas; las onomatopeyas que sí aparecen, "uno de los componentes literarios del cómic" (Barral, 2024), son para expresar el esfuerzo que hacen los personajes o el sonido del arma que disparan.

Después de la publicación original, el autor realizó un número inédito que se incluyó en la antología preparada por Bernardo Fernández (BEF) en 2018, titulado "La infancia del héroe" (pp. 1A-32A). En este número se narra un origen de la figura de Chanoc distinto al anterior. Aquí se muestra a un Chanoc joven divirtiéndose con sus amigos y dando muestras de alto compañerismo. Chanoc resalta en todos los deportes, especialmente nadando ("en el agua es un pez" [Mora, 2018, p. 1A]). Regresa a su casa pensando que sus padres, a quienes ama mucho, estarían con pendiente. Al llegar se encuentra con un evento impresionante: el brujo Argos intentando abusar de su madre. De inmediato, llega su padre y se inicia una pelea entre ambos. A través de viñetas cargadas de onomatopeyas y gritos, el lector presencia cómo Argos, con un puñal, mata a madre y padre. Luego de jurar vengar la muerte de sus padres, Argos persigue a Chanoc para también acabar con él. Al final de la 


\section{Revista Iberoamericana de las Ciencias Sociales y Humanísticas}

persecución, Chanoc, aterrorizado, se ve acorralado entre Argos y el mar lleno de tiburones y decide lanzarse al mar. En la cartelera, el narrador muestra empatía con el personaje y describe la acción de manera poética: "Ya no luchaba, su cuerpecito se abandonó al vaivén de las azules aguas" (Mora, 2018, p. 15A). Enseguida, otra cartelera rompe la tragedia con un dicho popular: "Rara vez el destino da segundas oportunidades como es este caso" (Mora, 2018, p. 15A). Y es que los compadres, Tsekub y el farero, que se encontraban pescando, rescataron a Chanoc. Durante el rescate, sin embargo, el farero pierde una pierna por la mordida de un tiburón (Tsekub lo llama en ese momento Pata Larga, apodo que lo acompañará toda la vida). Chanoc, bajo la custodia de Tsekub, su padrino, empieza a conocer el escenario de sus aventuras en el resto de la historieta: el mar y la selva. En la selva se encuentra a un jaguar, a un tapir o danta, a las guacamayas, al cocodrilo. Su primera aventura inicia cuando es mordido por una serpiente coralillo. Es rescatado y curado por el esotérico Nimbus.

Figura 2. Chanoc. Aventuras de mar y selva

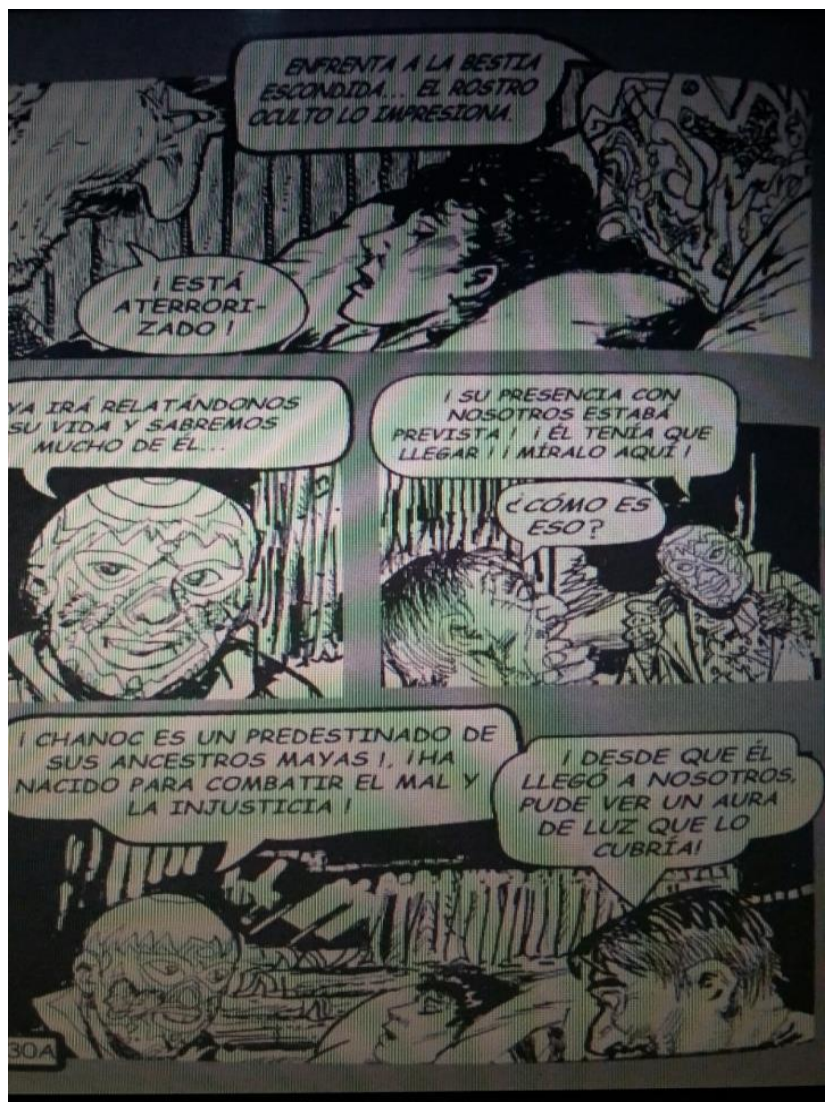

Fuente: Mora (2018, núm. 1, p. 30) 


\section{Revista Iberoamericana de las Ciencias Sociales y Humanísticas}

ISSN: $2395-7972$

En la figura 2, correspondiente a la página 30 del primer número, se visualiza un cartucho que enlaza las viñetas sobre el sufrimiento de Chanoc y los esfuerzos del curandero por sanarlo, seguido de las viñetas que muestran la preocupación de Tsekub porque Chanoc no aparece. Y es precisamente Nimbus quien revela a Tsekub los secretos acerca de Chanoc, le explica que Chanoc cumple leyes inmutables, que tiene una espiritualidad poco común por ser el heredero y el predestinado de la grandeza maya para combatir el mal y la justicia, que está relacionado con el cosmos e integrado a la mente universal que lo protegerá siempre (Mora, 2018, pp. 29A-31A).

Con esta nueva versión sobre los orígenes de Chanoc, se insiste en los buenos sentimientos de Chanoc, pero también en los deseos de venganza. Finalmente, se le otorga un origen divino al ser descendiente y el elegido por sus ancestros mayas, eso lo aleja de ser un humano normal para convertirlo en un héroe fuera de lo común, aunque no posee ningún tipo de poderes. El nombre Chanoc proviene de un dios de la mitología maya, cuyo color distintivo es el rojo, por eso Chanoc porta una playera roja (Geochinox, 2017). El color que pertenece a las categorías de macrounidades cumple con su función significativa (Bonilla, 2017) al estar relacionado directamente con la mitología maya.

En el último número de esta antología, también inédito (nunca fue publicado ni se mandó a la imprenta), con argumento de Martha Mora y diálogos de Pablo Rodríguez, titulado “Argos el villano" (Mora, 2018, cap. 10, pp. 1J-32J), se describe cómo durante 20 años el sentimiento de la muerte de sus padres ha perseguido a Chanoc. Este sentimiento es tan fuerte que, a pesar de haber viajado a la India con el objetivo de encontrar la paz mediante la meditación y el yoga, no logra deshacerse de él y decide regresar a Ixtac. Chanoc está convencido de que matar a Argos es la única forma de conseguir el olvido. Finalmente, un día lo encuentra y comienza a pelear cuerpo a cuerpo con él. La pelea es representada en viñetas repletas de figuras cinéticas, líneas continuas para mostrar los movimientos violentos. Durante el enfrentamiento, Argos, viéndose en desventaja, lanza un polvo a los ojos de Chanoc, lo que le provoca monstruosos visiones. Argos mismo se convierte en monstruo (recordemos que en el primer número lo presentan como el brujo Argos), sin embargo, Chanoc no deja de golpear y, finalmente, dando golpes con un palo, saca a todos los monstruos y quedan solo Argos y él frente a frente. Chanoc está a punto de matarlo con un cuchillo, pero muy a tiempo intervienen su padrino Tsekub y el esotérico 
Revista Iberoamericana

de las Ciencias Sociales y Humanísticas

ISSN: $2395-7972$

Nimbus, quienes le recuerdan que esa no es su misión, que él está hecho "para hazañas de justicia y bondad" (Mora, 2018, p. 32J). Aunque el deseo de venganza ha acompañado a Chanoc durante 20 años, la obediencia a su padrino lo salva de cometer un crimen. Chanoc posee un temperamento impulsivo, sí, pero a la vez es prudente. También es fuerte, caballeroso, atento, valiente y justiciero.

Figura 3. Portada del Cap. 7, "Los locos asociados", del libro Chanoc. Aventuras de mar y selva

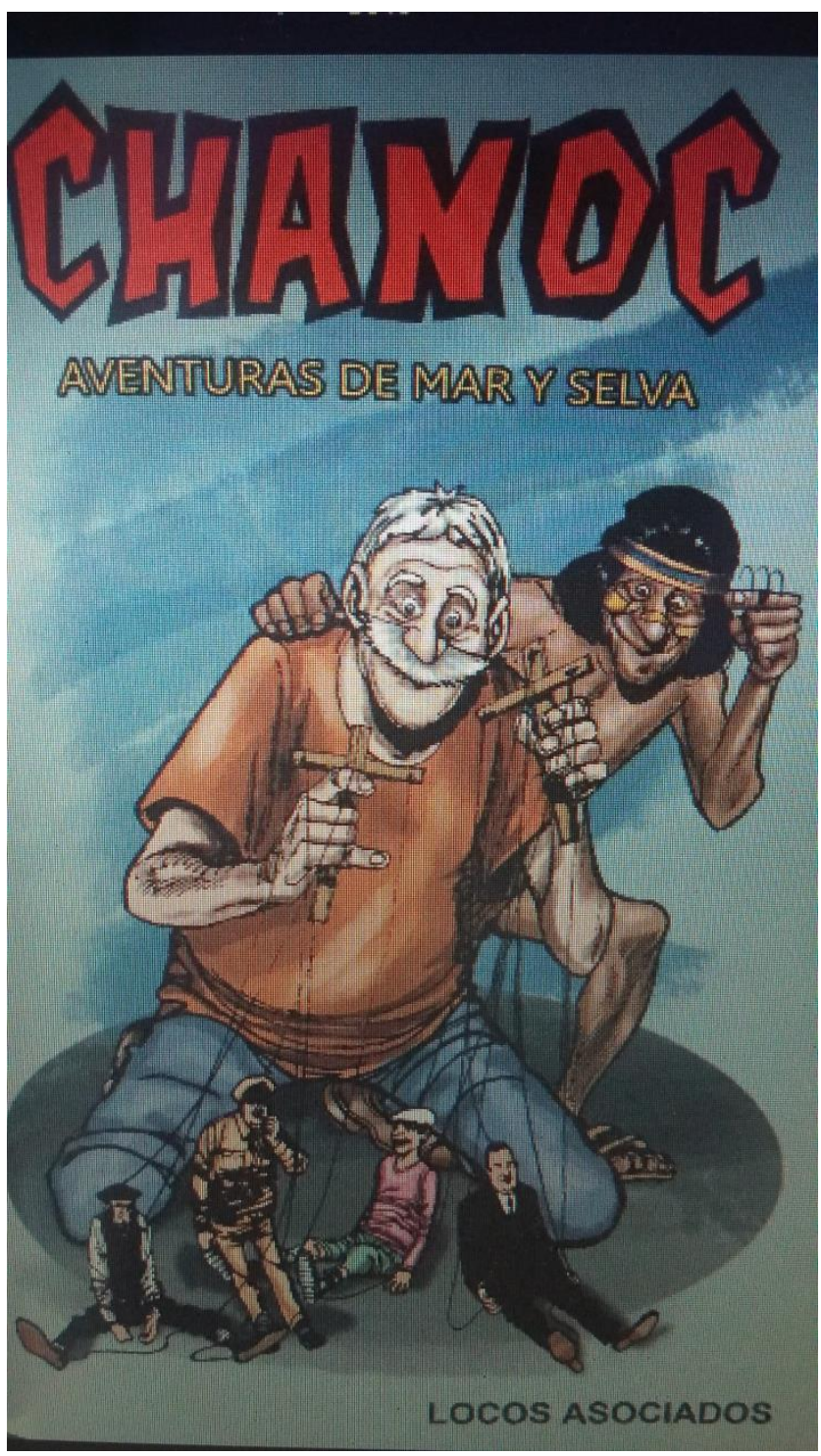

Fuente: Mora (2018) 


\section{Revista Iberoamericana \\ de las Ciencias Sociales y Humanísticas}

ISSN: $2395-7972$

\section{Tsekub, una caracterización del socio épico de Chanoc}

En la figura 3, correspondiente a la potada del capítulo 7, se observa en primer plano la imagen del personaje llamado Tsekub. En este apartado, se analizarán, con el método estilístico, los atributos de este personaje sui generis: su simiente picaresca, su entorno ficcional y los elementos contextuales de época que conforman un microcosmos muy particular de la mexicanidad; la dicotomía y simbiosis con el héroe Chanoc y su rol como socio y aliado; así como su estética dionisíaca caracterizada por el desenfreno. Se trata de características que, en conjunto, lo convierten en uno de los personajes más significativos de esta épica tropical en forma de historieta.

Si bien Tsekub encarna una figura de autoridad parental para Chanoc, a quien cariñosamente llama su "cachorro", nunca renuncia a su propia realización como personaje ni a sus motivaciones más vitales: el amor a las mujeres, el acceso fácil al dinero, la holganza, la fama personal y el gusto asiduo por el "cañabar", un destilado de caña de alta graduación alcohólica propio de la región de Ixtac, la ficticia aldea de pescadores (ubicada hipotéticamente en alguna región caribeña del Golfo de México, al sureste del país), donde pasan él y Chanoc sus días entre la exuberancia del mar y la selva, amenazados cotidianamente por los exóticos seres que pueblan este indómito paraíso lleno de vida y color: jaguares, panteras, serpientes, arañas, tiburones, pulpos gigantes y extraños y belicosos curanderos, caníbales y pigmeos.

Se tomará como referencia para este análisis estilístico la caracterización del personaje de Tsekub a lo largo de todas las ediciones de la historieta. Se toma como ejemplo el episodio titulado "Locos asociados", publicado originalmente el 14 de marzo de 1969 y que también forma parte de la compilación conmemorativa preparada por BEF, Chanoc. Aventuras de mar y selva, publicada en 2018 por la editorial Porrúa (cap. 7, pp. 1G-32G). El astuto Tsekub hace uso de su ingenio para desarrollar un negocio redituable a costa de la salud mental de cuatro pobladores adinerados de Ixtac: el funcionario portuario, Anclitas; el franquista tendero español, Baturro; el presidente de la Asociación Totonaca de Futbol de Ixtac, Cañeiro; y el entrenador del equipo de futbol local, Nacho Reyez. Para ello, Tsekub se vale de los "miedos" de estos personajes. Los desquicia mediante el uso de trucos y animales para generar supuestas alucinaciones y tergiversa la prensa escrita del pueblo mediante noticias falsas que conmocionan a sus víctimas: la caída del régimen de 


\section{Revista Iberoamericana}

de las Ciencias Sociales y Humanísticas

ISSN: $2395-7972$

Franco en España y la visita a Ixtac de la selección olímpica de futbol de Japón que recientemente había derrotado vergonzosamente al equipo de Ixtac. El negocio consiste en cobrarles a estos personajes un tratamiento de electroshocks de anguila eléctrica para curarlos de su supuesta locura. Para ello, Tsekub se asocia con el médico brujo, dueño de las anguilas. El negocio se viene abajo cuando los truhanes no se ponen de acuerdo en el monto que cobrarán por el "tratamiento" y Tsekub afronta las pérdidas de su inversión. El capítulo concluye con un robo que el jefe de la tribu de pigmeos hace a Tsekub y la oportuna intervención de Chanoc para restituir el orden y castigar a los ladrones pigmeos que le han robado diamantes falsos ocultos en una cueva submarina al iluso Tsekub.

\section{Tsekub, el pícaro}

El viejo Tsekub aspira a vivir a expensas de los demás a través del ingenio fraudulento, muy característico de los pícaros de cepa pura, que siempre tienen apetito, sed y ganas de reconocimiento fácil. Para lograr su fin, esgrime una serie de descabelladas iniciativas que en un principio resultan aparentemente exitosas, pero conforme se desarrollan lo conducen al fracaso y al castigo de la inmoralidad que las alimentó.

En el capítulo de referencia, Tsekub se asocia con un médico brujo poseedor de unas anguilas eléctricas con el fin de montar un negocio consistente en curar la locura y el estrés de los pacíficos habitantes de Ixtac y poder cobrar una suma jugosa por el "tratamiento" de electroshocks que a la postre les devuelvan el juicio. Sin embargo, el primer problema es que en Ixtac no hay locos, y si no los hay entonces hay que crearlos.

Tsekub entiende que para poder curar primero tiene que enfermar a sus futuros pacientes. Y este es el trabajo que realizará el viejo para generar una clientela redituable: seleccionar a aquellos prospectos de locos con el suficiente dinero que garantice jugosas ganancias. Para ello, como ya lo mencionamos anteriormente, el viejo juega con los miedos más comunes de sus víctimas, valiéndose de animales y recursos que les hagan perder el juicio e incluso tomando por asalto el periódico del pueblo (El Difamen) para difundir noticias falsas: la muerte del generalísimo Franco y el regreso de un temible equipo de futbol a Ixtac.

Las víctimas son: 


\section{Revista Iberoamericana \\ de las Ciencias Sociales y Humanísticas}

ISSN: $2395-7972$

a) El oficial Anclitas, funcionario portuario en Ixtac. Jovial y rechoncho padre de familia al que Tsekub le hace creer que está sufriendo alucinaciones al cambiar la pasta dentífrica de la víctima por Resistol (pegamento) y al introducir en su cama un caimán amaestrado que el propio Tsekub ha regalado al pequeño hijo del oficial.

b) El tendero Baturro, el dueño del almacén "El Perico Marinero". Un avaro inmigrante español partidario de Franco, que al leer en el periódico manipulado por Tsekub sobre la falsa muerte del generalísimo, cae en un estado suicida, al creer que con la caída del dictador perderá su dinero ahorrado en Andorra.

c) El entrenador Nacho Reyez, eterno entrenador de la selección de futbol de Ixtac, quien pierde el juicio al leer también en el diario la falsa noticia que anuncia el arribo al pueblo del equipo olímpico de Japón que recientemente los derrotó por un marcador muy abultado.

d) El maestro Cañeiro, presidente de la Asociación Totonaca de Futbol de Ixtac, que lee también la falsa noticia arriba mencionada, enloquece al creer que sus días como dirigente futbolístico están contados si otra vez es derrotado el seleccionado de la asociación que él preside.

Tsekub recoge en una carreta que ha rentado a todos los locos. Atados con una camisa de fuerza, son llevados a la clínica antiestrés montada en colaboración con el médico brujo a las afueras del pueblo. Los dementes imaginarios son sometidos a la violenta corriente que producen las anguilas. Sin embargo, el brujo cobra a cada uno solo cinco pesos por el tratamiento, cuando Tsekub esperaba cobrar 500 pesos por cada uno. Tsekub se da cuenta de que la inversión no se garantizará con tan baja cuota y se enoja con su socio.

Para pagar la renta del caballo y la carreta, Tsekub nada a la cueva submarina donde oculta un tesoro, pero se da cuenta de que alguien ha dado con el escondite y ha robado los diamantes ocultos. El viejo, entristecido, cuenta todo a su ahijado Chanoc, quien realiza pesquisas y da con los culpables: el rey de los pigmeos y su chamán. Chanoc se da cuenta de que los diamantes no son sino vidrio barato y con humor engaña y castiga a los pequeños ladrones, quienes reciben circunstancialmente su castigo cuando, al huir por el río, son arrastrados a una peligrosa cascada. 


\section{Revista Iberoamericana \\ de las Ciencias Sociales y Humanísticas}

ISSN: $2395-7972$

Tsekub también recibirá su castigo, ya que cuando regresa el médico brujo le dice que ha reconocido su error, y que ahora cobrará 500 pesos por tratamiento. Lo malo para Tsekub es que el brujo lo ha elegido a él como primer cliente.

\section{Tsekub en Ixtac, el microcosmos de la mexicanidad}

Ixtac, la aldea de pescadores en el Caribe mexicano, aparece en la saga de Chanoc como un microcosmos del México de finales de la década de los 60, donde se vive la paz y la bonanza del final del periodo nacional conocido como el desarrollo estabilizador, caracterizado por un repunte general de las condiciones de vida de la población, la modernización infraestructural, las altas tasas de natalidad, la estabilidad política de un partido perpetuado en el poder por más de 50 años mediante el fraude electoral y la represión social (la estudiantil de 1968, por ejemplo), así como por una manipulación gubernamental de los medios informativos, que es aludida aquí por la manera en que Tsekub altera las noticias de la prensa. Un país dominado ya por la televisión y la cadena Televisa que, asociada al Gobierno, acalla las inconformidades, suprime los actos represivos y moldea las conciencias a través de las telenovelas y los partidos de futbol, negocios que alimentan los sueños y las esperanzas sentimentales de una población mayoritariamente inculta.

Chanoc refleja, a través de las situaciones y los personajes que pueblan sus páginas, ese México de paz silenciada donde aún operan estereotipos como el burócrata en ascenso (el oficial Anclitas), el gachupín acaparador (el español tendero Baturro), el entrenador nacional (Nacho Reyes, que hace referencia a Nacho Trelles, entrenador de la selección mexicana en los mundiales de Chile 1962 e Inglaterra 1966), o del empresario televisivo metido a presidente de la federación de futbol, el maestro Cañeiro (quien hace también referencia a Cañedo, empresario de Televisa y presidente de la Federación Mexicana de Futbol, futuro artífice de la Copa Mundial realizada por México en 1970). 


\section{Chanoc y Tsekub, el apolíneo y dionisiaco tropical}

Chanoc, el héroe "apolíneo" (Eco, 2010), un mocetón guapo y atlético, portador de todas las aspiraciones físicas y morales de su colectivo, servicial, intrépido, noble, abstemio, galante, discreto, generoso, valiente y justiciero, tiene en Tsekub Baloyán, su viejo padrino, a su exacto contrario.

Tsekub "no es virtuoso" (Eco, 2007), pero sí amoroso en defender y prevenir a su hijo putativo de las maldades del mundo que el viejo, revestido de experiencia, ve de manera más real y humana que su propio protegido. Tsekub es desconfiado, sabe que a veces hay que alejarse de la recta virtud para lograr lo que se quiere, sobre todo en un medio donde el que no tranza (término mexicano para referirse al engaño, al fraude, a la mentira) no avanza.

Es en la tipología estética de Nietzsche un personaje de estética dionisíaca que, mediante el humor a veces grotesco y por lo regular festivo, intenta llegar siempre por el camino del fraude a la consumación de sus fines: el amor femenino, la comida, la bebida y el dinero (Eco, 2007). Tsekub, también tiene la conciencia y la certidumbre de que su ahijado, el imperturbable y generoso Chanoc, lo salvará oportunamente de cualquier conflicto, no sin antes regañarlo, así sea de forma cariñosa, haciéndole ver sus errores.

Tsekub es, dentro del camino del héroe Chanoc, un recurso más para aleccionar a los truhanes de que en este mundo, por más corroído de injusticia que esté, el bien siempre triunfará sobre el mal. Es, parece ser, la mayor lección que se recrea capítulo a capítulo en Chanoc, la historieta mexicana de aventuras por antonomasia. 
Revista lberoamericana

de las Ciencias Sociales y

Humanísticas

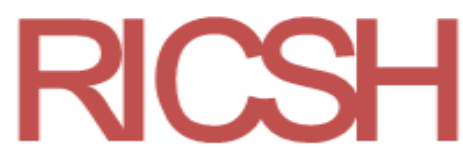

ISSN: $2395-7972$

Figura 4. Portada del capítulo 2, "El animal más venenoso del mundo", del libro Chanoc.

Aventuras de mar y selva.

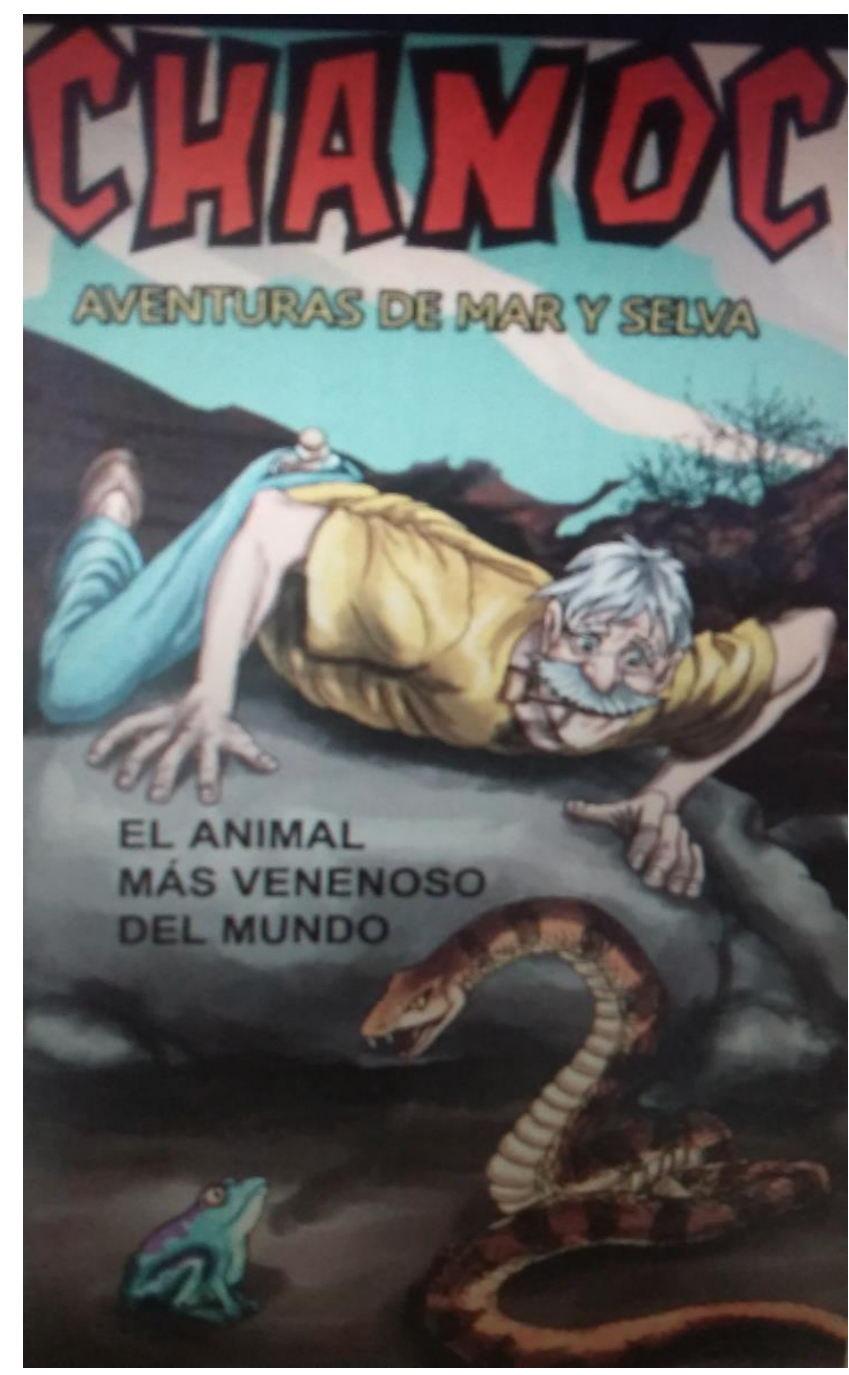

Fuente: Mora (2018)

\section{EI lenguaje popular citadino y el lenguaje científico en el número "El animal más venenoso del mundo" de Chanoc}

En la figura 4, correspondiente a la portada del capítulo 2, ilustra a Stsekub que observa a una serpiente. En este apartado, como lo anticipa su título, los lenguajes citadino y científico presentes en el número titulado "El animal más venenoso del mundo" son analizados con el método narratológico. En dicho número, Stekub, el padrino y guía de Chanoc, le enseña a Poco Pelo Pelch una falsa fórmula mágica para hacer crecer el pelo, al estilo de un bálsamo de Fierabrás quijotesco, y a cambio Poco Pelo le muestra la ubicación 


\section{Revista Iberoamericana de las Ciencias Sociales y Humanísticas}

ISSN: $2395-7972$

de la mina de diamantes de los hermanos caníbales Puk y Suk, quienes, al darse cuenta, tratan de impedirlo, no tanto porque les roben sus tesoros, sino porque a la entrada de la cueva se encuentra una rana kokoi, "el animal más venenoso del mundo". A través de todo el número veremos las peripecias de los hermanos para evitarlo y cómo Tsekub, acompañado de Memo Cochambres, logra salir ileso de la aventura.

Chanoc tuvo su aparición y popularidad cuando los mejores villanos eran los felinos y otros animales salvajes. Influido en gran medida por la historieta de Tarzán, el autor exploró con éxito indiscutible la relación estrecha entre la naturaleza, poniendo énfasis en el cuidado que debemos tener con el medio ambiente (Fernández, 2018, p. 48).

No es nada nuevo decir que el lenguaje popular forma parte de la cultura oral. De hecho, en las sociedades ágrafas las funciones a veces asignadas a la escritura a menudo son cumplidas por formas orales de gran sutileza y fuerza. "La escritura influye y altera estas formas, en particular por la vía de ampliar el conjunto de recursos empleados para convertir los textos en objetos del discurso" (Olson y Torrance, 1998, p. 14).

Existe una opinión generalizada de que la cultura escrita y la propagación de la lectura y la escritura han dado origen a formas particulares de conciencia propias del pensamiento occidental, pero Feldman (citado en Olson y Torrance, 1988, p. 15) sostiene que la distinción entre decir-significar y texto-interpretación no pueden ser exclusivas de las culturas con escritura, sino que este es un aspecto universal del lenguaje. Como prueba de ello muestra los diferentes registros presentes en el discurso oral en las sociedades llamadas tradicionales (ágrafas), en las que los hablantes emplean tipos especiales de discursos y determinados supuestos interpretativos para abordar diferentes clases de discursos como la oratoria o rituales.

El cómic transcribe la oralidad, de ahí que, aunque aparezca la escritura, esta intente transmitir lo más fiel posible los rasgos del lenguaje oral y, en el caso de nuestro cómic, de la cultura popular. El objeto de análisis es la particular forma de mezclar en Chanoc un lenguaje oral con un lenguaje científico y literario.

Con el empleo de un "lenguaje connotado, de un contexto cultural específico" (Cuñarro y Finol, 2013: 288), al recitar una parte de un libro, en una primera conversación Poco Pelo trata de convencer a Rogaciana, llamada por el narrador, que emplea una 


\section{Revista Iberoamericana de las Ciencias Sociales y Humanísticas}

lingüística retórica, como "ninfa del nacimiento de río", con la estrofa clásica del Don Juan Tenorio de Zorrilla:

Poco Pelo: — ¿ ¿No es verdad, ángel de amor, que en esta apartada orilla, más claro la luna brilla y se respira mejor?"

A lo que ella desde una postura airada le responde:

Rogaciana: - Yo ando tras los huesos de Tsekub.

Poco Pelo: — ¿Y qué tiene él que no tenga yo?

Rogaciana: -Pelo, entre otras cosas.

Poco Pelo: - Sí, ando medio fallo de pasto.

Ante esta situación, los lectores nos encontramos con la respuesta graciosa, la comparación entre pelo y pasto, "manipulando la asociación de significados" (Cuñarro y Finol, 2013, p. 287). En este caso, el empleo de las figuras retóricas es crear un momento hilarante. Si se recuerda que la época de mayor fama de este cómic fueron las décadas de los 70 y 80 del siglo XX, se podrá entender que algunas de estas frases populares hayan pasado de moda y ahora solo sean recordadas por gente que le tocó vivir en esos años.

Rogaciana también le reclama que no tenga perfil griego; a lo que él contesta que lo tiene antropopiteco, comparándose a sí mismo con un chimpancé. Ambas frases elaboradas con sintagmas fijos. Es así como en la primera página vemos la mezcla de diferentes registros lingüísticos en unos personajes que viven en medio de la selva exótica del sureste mexicano y que escasamente tendrían acceso a discursos que no fueran más allá del mundo cotidiano dominado por la oralidad y la popularidad del discurso.

Igualmente, se puede encontrar en el cómic referencias a los acontecimientos de la época, por ejemplo, a artistas y futbolistas famosos: Raphael, Calos Lico o el futbolista Borja son mencionados por los gemelos caníbales cuando su pequeño televisor se descarga y van con el médico brujo del lugar para que les cargue las pilas, situación incoherente en un lugar en el que seguramente no llegaba la señal de la televisión. Aquí también es importante destacar que entre ellos se llaman brother, un vocablo citadino que se puso de moda en los años 70.

En Chanoc se reproducen onomatopeyas, pero también se dan datos precisos sobre el nombre de las especies o su velocidad, su potencial veneno, etc. 
Revista Iberoamericana

de las Ciencias Sociales y

Humanísticas

ISSN: $2395-7972$

“Sabes que pusimos a una rana "phyllobates latinasus” a cuidar el túnel de la entrada?", le comentan los gemelos a Poco Pelo cuando se enteran de que este le ha dado a Tsekub la ubicación de la mina de diamantes. A lo que él contesta: "No creo que la rana sea buena vigilante". Uno de los gemelos ríe y dice: "Explícale a este tarado lo que hace nuestra batracia”, y se da una explicación sobre esta rana y por qué se le conoce como el animal más venenoso del mundo. "Se le conoce vulgarmente con el nombre de kokoi, su veneno es tan intenso que con 200 millonésimas de gramo, pone frío a un tapir". "O a un hombre", contesta el gemelo (Fernández, 2018, p. 58-59).

Los cuadros donde interviene el narrador también sustentan la mezcla de registros: el lenguaje urbano, que nos ubica más en una gran urbe que en una selva, el rural, por el conocimiento de la naturaleza, y el científico, porque a pesar de que los personajes son aparentemente seres sin ninguna formación académica explican los nombres científicos y señalan con gran precisión de tipo numérico la velocidad o el alcance del daño causado por un veneno. En las descripciones hechas por el narrador, hay certeza y el uso de un lenguaje técnico que revela conocimiento del arte de la narración, por ejemplo:

La cascabel llega intempestivamente, de inmediato pone el cuello en $s$ para lanzar un fulminante ataque contra la kokoi, pero la pequeña lanza su letal saliva contra la víbora de cascabel y la batracotoxina penetra en la piel del reptil y produce parálisis inmediata (Fernández, 2018, p. 65).

Palabras como rorro, alusiones a los hippies y su excéntrica vestimenta colorida, o la frase en la que Tsekub le dice a Poco Pelo que con el tónico se pondrá como Beatle, revelan cómo, a pesar de que Chanoc lleve el subtítulo de "Aventuras de mar y selva", hay detrás un guionista a quien se le filtran usos del lenguaje citadino y mezcla de cultura oral con escrita, datos y expresiones populares con otros que nos acercan a un conocimiento científico del mundo. Quizás de allí surgió su éxito, porque representaba al hombre citadino ansioso de vivir aventuras exóticas que solo a través del cómic eran posibles. 


\section{Discusión}

Este trabajo está delimitado al estudio de las características de entretenimiento y enseñanza en el cómic titulado Chanoc. Aventuras de mar y selva, del mexicano Ángel Mora. El primer número del cómic apareció en 1959 y desde entonces circuló durante 20 años. Las fortalezas de este trabajo se centran en la aplicación de tres métodos de análisis: la exégesis en la construcción del personaje; la estilística en el marco ficcional, los elementos contextuales y el microcosmos de la mexicanidad, y la narratología en el análisis del lenguaje popular citadino y el lenguaje científico. Se trabajaron los aspectos relacionados con la construcción del personaje principal, la figura del héroe y el lenguaje popular. Se tuvo en cuenta el contexto histórico en el que fue escrito y al público al que iba dirigido. Las áreas de debilidad son aquellas que, por la delimitación temática, no se trabajaron en este estudio, por ejemplo, los problemas políticos de México en ese momento histórico, tampoco no se profundizó en aspectos sociales y culturales, ya que este estudio se centra principalmente en los aspectos de entretenimiento y función didáctica de la historieta.

\section{Conclusión}

El cómic Chanoc. Aventuras de mar y selva cuenta con elementos de la época que sirven como referentes para realizar una crítica social del México de los años 60 y 70 del siglo XX, mayormente a través de Tsekub, el personaje picaresco representante de la mexicanidad. El cómic estaba dirigido principalmente a los jóvenes citadinos para conocer y crear conciencia sobre el cuidado de la flora y la fauna, ofrece también lecciones sobre el comportamiento de los animales. El cómic, que en México funcionó como un medio de comunicación de masas, y sirvió para reforzar el hábito de la lectura, estaba escrito con un lenguaje popular, como parte de la cultura oral, con registros del lenguaje urbano intercalado con un lenguaje científico y literario, y tenía como función entretener y enseñar a la vez, con lecciones sobre la moral, la justicia y el respeto por la vida.

El cómic Chanoc, a través de personajes representativos, instruye a los jóvenes por medio de la crítica social, crea conciencia y da lecciones sobre el comportamiento de los animales y el cuidado de la naturaleza. 


\section{Futuras líneas de investigación}

Este trabajo aporta elementos interesantes para realizar en otras investigaciones sobre este cómic, Chanoc, u otros similares en futuras líneas de investigación. Entre los aspectos interesantes, que por el momento escapan al alcance de este primer trabajo, pero que deberán ser analizados en trabajos adicionales, se encuentra primeramente el análisis de los códigos icónicos, así como las narraciones que hacen referencias a la sociedad y a la política mexicana de la época, a través de la metodología empleada por la sociocrítica de Edmond Cros (2009) sobre los patrones de la imagen y sus comportamientos, los postulados de Roland Barthes (2005) sobre la huella de la imagen, su funcionamiento y relación con el tiempo y los cuatro puntos para el acercamiento analítico propuestos por Roberto Aparici (2006): comunicación y realidad, elementos básicos para el estudio de la imagen, la realidad representada y elementos de comunicación.

\section{Referencias}

Aparici, R. (2006). La imagen: análisis y representación de la realidad. Barcelona, España: Gedisa.

Barral, F. J. (2014). Analizar un cómic y entenderlo. La mar de libros. Recuperado de https://lamardelibros.wordpress.com/2014/10/31/analizar-un-comic-y-entenderlo/.

Barthes, R., (2005). La cámara lúcida. México: Gustavo Gilli.

Bonilla, Á. (2017). Pautas para analizar un cómic. Recuperado de https://prezi.com/z-ou_k7qmsn/pautas-para-analizar-un-comic/.

Ceballos, N. (18 de octubre de 2018). Cómo leer un cómic. Revista GQ. Recuperado de https://www.revistagq.com/noticias/cultura/articulos/como-leer-un-comiccorrectamente/31305.

Camarada05. (2014). Chanoc. Cómic clásicos e historieta. Recuperado de https://historietanovaro.blogspot.com/2014/03/chanoc-no-001-1959.html.

Cros, E. (2009). La sociocrítica. Madrid, España: Arcolibros.

Cuñarro, L. y Finol, J. E. (2013). Semiótica del cómic: códigos y convenciones. Signa: Revista de la Asociación Española de Semiótica, (22), 267-290.

Eco, U. (1986). La estructura ausente. Introducción a la semiótica. Barcelona, España: Lumen. 
Eco, U. (2007). Historia de la fealdad. Barcelona, España: Lumen.

Eco, U. (2010). Historia de la belleza. Barcelona, España: Lumen.

Fernández, B. (2018). ¡Chúpale que se acaba! En Mora, A., Chanoc. Aventuras de mar y selva. México, Editorial Porrúa.

Geochinox. (2017). Mitología heroica mexicana. Mexaverso. Recuperado de http://campeonesjusticieros.blogspot.com/2017/08/chanoc.html.

L. (2014). El origen de la historieta o cómic y su evolución. Entre libros y letras. Recuperado de https://www.iberlibro.com/blog/index.php/2014/09/11/el-origen-dela-historieta-o-comic-y-su-evolucion/.

Maza, A. E. (2013). Un acercamiento al cómic: origen, desarrollo y potencialidades. Perspectivas Docentes, (50), 12-16.

Mora, A. (2018). Chanoc, aventuras de mar y selva. México: Porrúa.

Morrison, F. (2017). La historia del cómic en México. Crush Comics. Recuperado de https://www.crushcomics.mx/blogs/news/la-historia-del-comic-en-mexico.

Olson, D. R. y Torrance, N. (comps.) (1998), Cultura escrita y oralidad. Barcelona, España: Gedisa editorial. 
Revista Iberoamericana

de las Ciencias Sociales y

Humanísticas

\begin{tabular}{|c|c|}
\hline Rol de Contribución & Autor (es) \\
\hline Conceptualización & $\begin{array}{l}\text { Marina Ruano Gutiérrez (Grado de contribución igual). } \\
\text { Irma Angélica Bañuelos Ávila (Grado de contribución igual). } \\
\text { Roberto Herrera Gallardo (Grado de contribución igual). }\end{array}$ \\
\hline Metodología & $\begin{array}{l}\text { Marina Ruano Gutiérrez (Grado de contribución igual). } \\
\text { Irma Angélica Bañuelos Ávila (Grado de contribución igual). } \\
\text { Roberto Herrera Gallardo (Grado de contribución igual). }\end{array}$ \\
\hline Software & $\begin{array}{l}\text { Marina Ruano Gutiérrez (Grado de contribución igual). } \\
\text { Irma Angélica Bañuelos Ávila (Grado de contribución igual). } \\
\text { Roberto Herrera Gallardo (Grado de contribución igual). }\end{array}$ \\
\hline Validación & Marina Ruano Gutiérrez \\
\hline Análisis Formal & $\begin{array}{l}\text { Marina Ruano Gutiérrez (Grado de contribución igual). } \\
\text { Irma Angélica Bañuelos Ávila (Grado de contribución igual). } \\
\text { Roberto Herrera Gallardo (Grado de contribución igual). }\end{array}$ \\
\hline Investigación & $\begin{array}{l}\text { Marina Ruano Gutiérrez (Grado de contribución igual). } \\
\text { Irma Angélica Bañuelos Ávila (Grado de contribución igual). } \\
\text { Roberto Herrera Gallardo (Grado de contribución igual). }\end{array}$ \\
\hline Recursos & $\begin{array}{l}\text { Roberto Herrera Gallardo (Grado de contribución igual). } \\
\text { Eduardo Ortiz Arámbula (Grado de contribución igual). }\end{array}$ \\
\hline Curación de datos & $\begin{array}{l}\text { Marina Ruano Gutiérrez (Grado de contribución igual). } \\
\text { Irma Angélica Bañuelos Ávila (Grado de contribución igual). } \\
\text { Roberto Herrera Gallardo (Grado de contribución igual). }\end{array}$ \\
\hline $\begin{array}{l}\text { Escritura - Preparación del } \\
\text { borrador original }\end{array}$ & $\begin{array}{l}\text { Marina Ruano Gutiérrez (Grado de contribución igual). } \\
\text { Irma Angélica Bañuelos Ávila (Grado de contribución igual). } \\
\text { Roberto Herrera Gallardo (Grado de contribución igual). }\end{array}$ \\
\hline $\begin{array}{l}\text { Escritura - Revisión y } \\
\text { edición }\end{array}$ & Marina Ruano Gutiérrez \\
\hline Visualización & $\begin{array}{l}\text { Marina Ruano Gutiérrez (Grado de contribución igual). } \\
\text { Irma Angélica Bañuelos Ávila (Grado de contribución igual). } \\
\text { Roberto Herrera Gallardo (Grado de contribución igual). }\end{array}$ \\
\hline Supervisión & Roberto Herrera Gallardo \\
\hline Administración de Proyectos & Roberto Herrera Gallardo \\
\hline Adquisición de fondos & Marina Ruano Gutiérrez \\
\hline
\end{tabular}


Revista Iberoamericana de las Ciencias Sociales y Humanísticas 